\title{
Effect of Two Different Types of Olympic Rotation Order on Cardiovascular and Metabolic Variables in Men's Artistic Gymnastics
}

\author{
by \\ Bessem Mkaouer ${ }^{1}$, Monèm Jemni², Helmi Chaabene ${ }^{3}$,Samiha Amara ${ }^{1}$,Ahmad Njah", \\ Mokhtar Chtara ${ }^{1}$
}

The rotation sequence-order differs from a gymnast to another according to the draw at the time of the qualifying competitions in men's artistic gymnastics. Only the six best gymnasts start on the floor exercises, the others could start on any of the other five apparatuses. It has been demonstrated that some gymnastics events are physiologically less taxing than others; hence some gymnasts could experience lower and/or higher levels of cardiovascular and metabolic stress compared to others, depending on the apparatus they start with. In this regard, the objective of this investigation was to compare cardiovascular and metabolic variables between two different types of Olympic rotation-order; one began with the floor exercises and the other began with the pommel horse. Six elite male gymnasts took part in this investigation. Heart rates, synchronized with real-time video acquisition, as well as capillary lactate concentration following each apparatus routine were monitored. Cardiovascular and metabolic stresses were significantly higher when gymnasts started their rotation with the pommel horse in all apparatuses except the pommel horse. The floor exercises' score was significantly affected when gymnasts ended up their competition on this apparatus. As a conclusion, starting gymnastics' competition on the floor exercises implicates less cardiovascular and metabolic stress associated with better performance compared with the other rotation order. As a matter of fact, best gymnasts who start on this apparatus could have a slight advantage compared with the other athletes.

Key words: gymnastics, heart rate, blood lactate, recovery, apparatus, score.

\section{Introduction}

It is well established that the manifestation of strength, power, flexibility, and muscular endurance is quite different from an apparatus to another in men's artistic gymnastics (Jemni et al., 2000, 2001, 2006). In this context, Grossfeld (2014), Papadopoulos et al. (2014) as well as Dallas and Kirialanis (2010) confirmed that some gymnastic apparatuses were more or less taxing than others. The highest cardiorespiratory stress associated with larger anaerobic contributions was noticed during the floor exercises routines (maximum duration of the routine is $70 \mathrm{~s}$ ), with maximal heart rates reaching $186 \pm 11 \mathrm{~b} \cdot \mathrm{min}-1$ and blood lactate values ranging from 6 to $11 \mathrm{mmol} \cdot \mathrm{l}-1$ (Jemni et al., 2000, 2003a, 2003b). High cardiorespiratory and metabolic stresses were also found during the pommel horse followed by the rings, high bars, and parallel bars routines. The average routine time of these four apparatuses is $45 \mathrm{~s}$. The less taxing routine was

\footnotetext{
1 - Department of Sports and Physical Activities, Higher Institute of Sport and Physical Education, Ksar Said, Manouba University, Tunisia.

2 - Department of Sport Science, College of Arts and Science, Qatar University, Doha, Qatar.

3 - Tunisian Research Laboratory "Sports Performance Optimization", National Center of Medicine and Science in Sports (CNMSS), Tunis, Tunisia.
} 
found to be the vault table, which lasts only from 4 to $6 \mathrm{~s}$. Hence, it is supposed that some gymnasts could get a physical advantage if they start their competition on the floor routine, however, those who finish on this apparatus could be the most penalized. Nevertheless, this hypothesis has never been confirmed scientifically. Jemni et al. (2000, 2003a, 2003b) have suggested an auto-recovery process that takes place during the vault event, which is scheduled as the 4th apparatus if gymnasts start with the floor exercises (around the middle of the competition).

The specificity of each apparatus makes artistic gymnastics a unique sport where each single preparation differs significantly from the other not only physically, but also mentally. Performance requirements on the rings, for instance, are purely based on both physical strength and power (Brewin et al., 2000). Additionally, the speed of the stretch and the nature of the contractions are different compared with those required for the vault, the pommel horse and the high bar seeing the aero-dynamic differences between the apparatuses. Arial complex figures add fear factor and major psychological stress on the gymnasts, hence they require considerable mental and psychological preparation at the earliest stage of specialization (Pineda-Espejel et al., 2013; Salmela, 2011). In all cases, gymnasts seek to focus on elegance and a technicality, moreover, an optimum forcevelocity, high level of flexibility, perfection and movement coordination combined with a great sense of harmony and creativity should be applied. These considerations are quite important, knowing that gymnasts have to compete in all the six apparatuses following very specific set order. The Olympic rotation order is always the same, but differs from a gymnast to another according to the draw at the time of the qualifying competitions (i.e., floor exercises, pommel horse, rings, vault, parallel bars, and horizontal bar). Only the six best gymnasts start on the floor exercises, the others could start on any of the five other apparatuses, however, they will all follow the same rotation order according to the rules.

Our review of the available literature showed that all authors who had investigated artistic gymnastics' metabolic and cardiovascular aspects followed the instructed routines imposed by the International Gymnastics Federation (FIG,
2009) that is to start by the floor exercise, followed by the pommel horse, rings, vault, parallel bars, and horizontal bar (Heller et al., 1998; Irurtia et al., 2007; Lange et al., 2005; Marina and Rodríguez, 2014). The question to answer was whether gymnasts' performance would be affected if they performed their six routines in two different rotation sequences? Additionally, could gymnasts who began on the floor exercises have any kind of physical and/or physiological advantage over the other gymnasts? Therefore, the objective of this investigation was to compare cardiovascular and metabolic variables between two different types of Olympic rotation order in men's artistic gymnastics; one began with the floor exercises and the other with the pommel horse. A secondary objective was to assess the effect of rotation order on performance.

\section{Methods}

Participants

Six elite-level male gymnasts (age: $20.91 \pm$ 2.31 years; body mass: $65.56 \pm 4.07 \mathrm{~kg}$; body height: $1.64 \pm 0.05 \mathrm{~m} ; \mathrm{VO}_{2 \max }: 52.25 \pm 3.60 \mathrm{ml} \cdot \mathrm{kg}$ ${ }^{1} \cdot \mathrm{min}^{-1}$ ) participated in this study (Table 1 ). The inclusion criteria were: to be ranked at an international level with participation in world cups and/or championships; average training time: $25 \pm 2$ hours per week; healthy without any muscular, neurological or tendon injuries. All participants were informed of the procedures, benefits, and possible risks of the study in advance. Each participant had to review and sign a participation consent form. The experimental protocol was performed in accordance with the Declaration of Helsinki for human experimentation and was approved by the local Ethics Committee of the Higher Institute of Sport and Physical Education of Ksar Said, Tunisia.

Experimental design and procedures

This study consisted of two random assessments conducted on two separate days with seven days apart. Assessments were carried out in the federal national gymnasium at the same time of the day (between 4:00 ${ }^{\mathrm{PM}}$ and 7:00 ${ }^{\mathrm{PM}}$ ). Both assessments were simulations of gymnastics competition. One of them (R1) was performed following the FIG's standard rotation order that began with the floor exercises (FX) and followed by the pommel horse $(\mathrm{PH})$, the rings $(\mathrm{SR})$, the vault (VT), the parallel bars (PB), and ended by 
the horizontal bar (HB). The other competition (R2) was also performed according to the FIG's standards, although it began with the $\mathrm{PH}$, followed by $\mathrm{SR}$, the VT, the $\mathrm{PB}$, the $\mathrm{HB}$, and ended with the FX. Gymnasts were given $45 \mathrm{~min}$ to warm up before the start of the competition. A specific $30 \mathrm{~s}$ warm up on the apparatus was also given to each gymnast before the so-called competition-test. The total time of each competition was approximately $1 \mathrm{~h} 40 \mathrm{~min}$.

The heart rate (HR) was recorded using a Polar Team Pro ${ }^{\circledR}$ heart rate monitor. Each apparatus' peak HR (HR peak) as well as recovery heart rates $1 \mathrm{~min}$ (HRrec1m) and $2 \mathrm{~min}$ (HRrec2m) after the completion of each routine were registered. Heart rates' recordings were synchronized with real-time video acquisition using two camcorders Sony DCR PC 108, 1CCD 1000000 pixels, SSC $1 / 4000$ per second, with minimal sensitivity of 1 lux and frequency of 30 $\mathrm{Hz}$. Video acquisition was used to determine the start and the end of each routine, hence enabling heart rate data synchronization during each apparatus exercises and the following recovery period.

A sample of capillary blood from the ear lobe was obtained $3 \mathrm{~min}$ after the end of each apparatus routine for blood lactate (BLa) concentration analysis. This later was performed using a portable blood lactate analyzer (Lactate Pro $^{\circledR}$ Kit, ARKRAY Factory, Inc. USA).

Six international judges, including two judges for the difficulty scores (D) and four judges for the execution scores (E) evaluated the gymnasts' technical performance according to the FIG's code of points (FIG, 2009). Each gymnast was required to perform exactly the same routines in both competitions.

Statistical Analysis

Data are reported as means \pm standard deviations and confidence intervals at the $95 \%$ level $(95 \% \mathrm{CI})$. Effect size $(d)$ was calculated using GPOWER software "Bonn FRG, Bonn University, Department of Psychology" (Erdfelder et al., 1996). The following scale was used to interpret $d$ : $<0.2$, [trivial]; $0.2-0.6$, [small]; $0.6-1.2$, [moderate]; $1.2-2.0$, [large]; and $>2.0$, [very large] (Hopkins, 2002; Scanlan et al., 2012). The normality of data distribution, estimated by the Shapiro-Wilk test, was not acceptable for all variables. Therefore, the non-parametric Wilcoxon
Rank-sum test was applied to compare the variables between the two different rotation sequences. Besides, delta-percentage $(\Delta) " \Delta(\%)=$ $\left[\left(R_{1}-R_{2}\right) / R_{1}\right] \times 100 "$ was calculated in order to evaluate the percentage of variation between the two rotation sequences (i.e., R1 and R2). The level of significance was set at $0.05 \%(p \leq 0.05)$. All analyses were performed using the Statistical Package for the Social Sciences version 20.0 (SPSS Inc., Chicago, IL, USA).

\section{Results}

Statistical analysis showed that the cardiovascular and metabolic variables were significantly different between the two rotation sequences. The raw data regarding the two types of the Olympic rotation order are displayed in Table 2. Table 3 shows the physiological variables (HR and BLa) and technical performance scores difference between the two rotations.

Floor Exercise

$\mathrm{HR}_{\text {peak }}$ was significantly different between both rotation sequences, with $\mathrm{R} 2$ showing higher values $[\Delta=2.83 \%, p<0.05]$ compared with $\mathrm{R} 1$. The same difference was also noted when comparing HRrec1m: [ $\Delta=4.69 \%, p<0.05]$ (Figure 1). Similarly, BLa was significantly higher during R2 compared to R1 [ $\Delta=15.38 \%, p<0.05]$ (Figure 2). However, the FX's score was significantly lower during R2 compared to R1 [ $\Delta=3.42 \%, p<0.05]$.

Pommel Horse

No significant difference was noticed between the two types of Olympic rotation with respect to the physiological responses and technical performance.

Rings

The only observed significant difference when comparing the SR routines between both rotations was the $B L a$ concentration being higher following R2 compared with R1 [ $\Delta=11.43 \%, p<$ 0.05] (Figure 2).

Vault

HR peak varied significantly during the two Olympic rotations, being higher during R2 compared with R1 $[\Delta=2.72 \%, p<0.05]$. The same outcome was also true for the HRrecm $[\Delta=4.74 \%, p$ $<0.05$ ] (Figure 1). Besides, BLa concentration varied significantly during the two sequences with greater values during R1 compared with R2 $[\Delta=14.87 \%, p<0.05]$ (Figure 2). 


\section{Parallel Bars}

Physiological variables varied significantly between the two types of rotations.

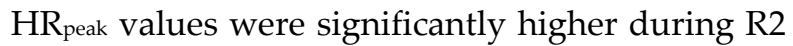
compared with R1 [ $\Delta=1.72 \%, p<0.05]$. Similarly, HRrec1m and HRrec2m were also higher during R2 compared with R1 $[\Delta=5.12 \%$ and $3.61 \%$, respectively, both $p<0.05$ ] (Figure 1).
Horizontal Bar

Only HRrec1m was significantly higher following R2 compared with R1 [ $\Delta=1.72 \%, p<$ 0.05] (Figure 1).

Performance (Scores)

Apart from the FX routines that significantly differed between the two sequences, all other apparatuses' scores were similar between the two rotations $(p>0.05)$.

\begin{tabular}{|c|c|c|c|c|c|c|c|c|}
\hline \multirow{2}{*}{\multicolumn{9}{|c|}{ Participants' characteristics. }} \\
\hline & & & & & & & & \\
\hline Gymnast & $\begin{array}{c}\text { Age } \\
\text { (years) }\end{array}$ & $\begin{array}{c}\text { Body } \\
\text { Mass } \\
(\mathrm{kg}) \\
\end{array}$ & $\begin{array}{l}\text { Body } \\
\text { Height } \\
(\mathrm{m}) \\
\end{array}$ & $\begin{array}{c}\mathrm{VO}_{2 \max } \\
\left(\mathrm{ml} \cdot \mathrm{min} \cdot \mathrm{kg}^{-1}\right)\end{array}$ & $\begin{array}{l}\text { HRrest } \\
\left(\mathrm{b} \cdot \mathrm{min}^{-1}\right)\end{array}$ & $\begin{array}{l}\mathrm{HR}_{\max } \\
\left(\mathrm{b} \cdot \mathrm{min}^{-1}\right)\end{array}$ & $\begin{array}{c}\text { BLarest } \\
\left(\mathrm{mmol} \cdot \mathrm{l}^{-1}\right)\end{array}$ & $\begin{array}{c}\text { BLa VO } 2 \text { max } \\
\left(\mathrm{mmol} \cdot \mathrm{l}^{-1}\right)\end{array}$ \\
\hline 1 & 24.25 & 70.79 & 1.71 & 54.64 & 62 & 198 & 2.90 & 12.70 \\
\hline 2 & 22.45 & 63.15 & 1.68 & 58.05 & 64 & 197 & 1.80 & 12.10 \\
\hline 3 & 21.52 & 66.07 & 1.64 & 48.63 & 63 & 198 & 1.90 & 11.80 \\
\hline 4 & 18.47 & 68.59 & 1.60 & 50.88 & 61 & 203 & 2.03 & 12.30 \\
\hline 5 & 18.33 & 59.21 & 1.58 & 49.03 & 60 & 207 & 2.16 & 11.70 \\
\hline 6 & 20.42 & 65.54 & 1.62 & 52.25 & 62 & 200 & 2.08 & 12.50 \\
\hline Mean \& & 20.91 & 65.56 & 1.64 & 52.25 & 62.00 & 200.50 & 2.15 & 12.18 \\
\hline $\mathrm{SD}$ & \pm 2.31 & \pm 4.07 & \pm 0.05 & \pm 3.60 & \pm 1.41 & \pm 3.83 & \pm 0.39 & \pm 0.38 \\
\hline \multicolumn{9}{|c|}{$\left(\mathrm{VO}_{2 \max }\right)$ Maximum oxygen uptake; $\left(H R_{\text {rest }}\right)$ Heart rate at rest; $\left(H R_{\max }\right)$ Maximal heart rate; $\left(B L a_{\text {rest }}\right)$} \\
\hline Blood lac & tecon & O & rest; (BL & $\begin{array}{l}\left.V O_{2 \max }\right) M a x \\
\text { with } V O_{2 m a}\end{array}$ & mal blood & lactate cor & centration & associated \\
\hline
\end{tabular}

\begin{tabular}{|c|c|c|c|c|c|c|}
\hline \multicolumn{7}{|c|}{ Descriptive statistics of the two types of the Olympic rotation order. } \\
\hline \multirow[t]{2}{*}{ Variables } & & $\begin{array}{c}\text { HRpeak (b·min } \\
1 \text { ) }\end{array}$ & $\begin{array}{l}\text { HRrec1m (b·min- } \\
1 \text { 1) }\end{array}$ & $\begin{array}{l}\text { HRrec2m }\left(b \cdot \min ^{-}\right. \\
1 \text { ) }\end{array}$ & $\begin{array}{c}\text { BLa (mmol.1- } \\
\text { 1) }\end{array}$ & Score (point) \\
\hline & & $\mathrm{M} \pm \mathrm{SD}$ & $\mathrm{M} \pm \mathrm{SD}$ & $\mathrm{M} \pm \mathrm{SD}$ & $\mathrm{M} \pm \mathrm{SD}$ & $\mathrm{M} \pm \mathrm{SD}$ \\
\hline \multirow{2}{*}{$\begin{array}{l}\text { Floor } \\
\text { Exercises }\end{array}$} & R1 & $185.20 \pm 11.67$ & $142.40 \pm 6.91$ & $122.40 \pm 7.19$ & $9.90 \pm 1.04$ & $12.86 \pm 0.90$ \\
\hline & $\mathrm{R} 2$ & $190.60 \pm 9.15^{*}$ & $149.40 \pm 4.61^{*}$ & $127.40 \pm 3.20$ & $11.70 \pm 1.51^{*}$ & $12.42 \pm 0.94^{*}$ \\
\hline \multirow{2}{*}{$\begin{array}{l}\text { Pommel } \\
\text { Horse }\end{array}$} & $\mathrm{R} 1$ & $157.80 \pm 6.90$ & $132.40 \pm 6.80$ & $113.80 \pm 7.32$ & $8.70 \pm 1.86$ & $12.02 \pm 1.36$ \\
\hline & $\mathrm{R} 2$ & $148.80 \pm 5.24$ & $130.60 \pm 2.40$ & $108.40 \pm 2.70$ & $7.40 \pm 1.17$ & $12.16 \pm 1.27$ \\
\hline \multirow{2}{*}{ Rings } & R1 & $181.60 \pm 12.74$ & $147.40 \pm 8.87$ & $122.00 \pm 2.91$ & $8.68 \pm 1.00$ & $10.10 \pm 1.02$ \\
\hline & $\mathrm{R} 2$ & $184.40 \pm 8.64$ & $147.6 \pm 5.03$ & $123.00 \pm 3.16$ & $9.80 \pm 0.97^{*}$ & $10.26 \pm 0.99$ \\
\hline \multirow{2}{*}{ Vault } & $\mathrm{R} 1$ & $171.40 \pm 10.06$ & $124.00 \pm 11.46$ & $106.00 \pm 10.19$ & $6.16 \pm 1.41$ & $13.00 \pm 0.78$ \\
\hline & $\mathrm{R} 2$ & $176.20 \pm 7.95^{*}$ & $119.80 \pm 2.49$ & $101.20 \pm 7.01^{*}$ & $5.38 \pm 0.51^{*}$ & $13.04 \pm 0.79$ \\
\hline \multirow{2}{*}{$\begin{array}{l}\text { Parallel } \\
\text { Bars }\end{array}$} & R1 & $171.40 \pm 6.18$ & $129.80 \pm 7.69$ & $122.20 \pm 9.68$ & $5.28 \pm 0.96$ & $11.32 \pm 0.59$ \\
\hline & $\mathrm{R} 2$ & $174.40 \pm 7.02^{*}$ & $136.80 \pm 8.78^{*}$ & $116.40 \pm 9.42^{*}$ & $5.44 \pm 0.49$ & $11.42 \pm 0.67$ \\
\hline \multirow{2}{*}{$\begin{array}{l}\text { Horizontal } \\
\text { Bar }\end{array}$} & $\mathrm{R} 1$ & $183.60 \pm 9.65$ & $160.40 \pm 6.50^{*}$ & $125.00 \pm 4.41$ & $9.04 \pm 1.51$ & $11.06 \pm 0.80$ \\
\hline & $\mathrm{R} 2$ & $185.40 \pm 8.20$ & $163.20 \pm 4.08$ & $127.60 \pm 2.60$ & $9.10 \pm 1.07$ & $11.02 \pm 0.82$ \\
\hline \multicolumn{7}{|c|}{$\begin{array}{l}\text { (R1) First order of rotation (floor exercises, pommel horse, rings, vault table, parallel bars and } \\
\text { horizontal bar); (R2) Second order of rotation (pommel horse, rings, vault table, parallel bars, } \\
\text { horizontal bar and floor exercise); (HRpeak) Peak heart rate; (HRrec1m) Recovery heart rate after } 1 \\
\text { min; }\left(H R_{\text {rec } 2 m}\right) \text { Recovery heart rate after } 2 \text { min; }(B L a) \text { Blood lactate concentration; }\left({ }^{*}\right) \text { Significant } \\
\text { at } p<0.05 \text {. }\end{array}$} \\
\hline
\end{tabular}


Table 3

Comparative statistics of the two types of the Olympic rotation order.

\begin{tabular}{lcccccccccc}
\hline \multirow{2}{*}{ Variables } & \multicolumn{2}{c}{ HRpeak } & \multicolumn{2}{c}{ HRrec1m } & \multicolumn{2}{c}{ HRrec2m } & \multicolumn{3}{c}{ BLa } & \multicolumn{3}{c}{ Score } \\
\cline { 2 - 9 } & $\mathrm{Z}$ & $d$ & $\mathrm{Z}$ & $d$ & $\mathrm{Z}$ & $d$ & $\mathrm{Z}$ & $d$ & $\mathrm{Z}$ & $d$ \\
\hline Floor Exercises & $-2.06^{*}$ & $2.10 \ddagger$ & $-2.04^{*}$ & $3.02^{\ddagger}$ & -1.08 & - & $-2.03^{*}$ & $3.28^{\ddagger}$ & $-2.07^{*}$ & $7^{2}$ \\
Pommel Horse & 0.54 & - & -0.67 & - & -1.62 & - & -1.67 & - & -0.73 & - \\
Rings & -0.94 & - & -0.37 & - & -0.96 & - & $-2.03^{*}$ & $14,96^{+}$ & -1.51 & - \\
Vault & $-2.02^{*}$ & $0,63^{\sim}$ & -0.96 & - & $-2.03^{*}$ & $1,49^{+}$ & $-2.06^{*}$ & $0,65^{-}$ & 0.70 & - \\
Parallel Bars & $2.04^{*}$ & $3,37 \ddagger$ & $-2.03^{*}$ & $1,82^{+}$ & $-2.03^{*}$ & $1.95^{+}$ & -0.68 & - & -1.51 & - \\
Horizontal Bar & -1.76 & - & $-2.06^{*}$ & $1,15^{-}$ & -1.75 & - & -0.40 & - & -0.55 & -
\end{tabular}

$(*)$ Significant at $p<0.05 ;(\ddagger)$ Very Large Effect Size; $(+)$ Large Effect Size; $(\sim)$ Moderate Effect Size; (HRpeak) Peak heart rate; (HRreclm) Recovery heart rate after 1 min; (HRrec2m) Recovery heart rate after 2 min; (BLa) Blood lactate concentration; (d) effect size.

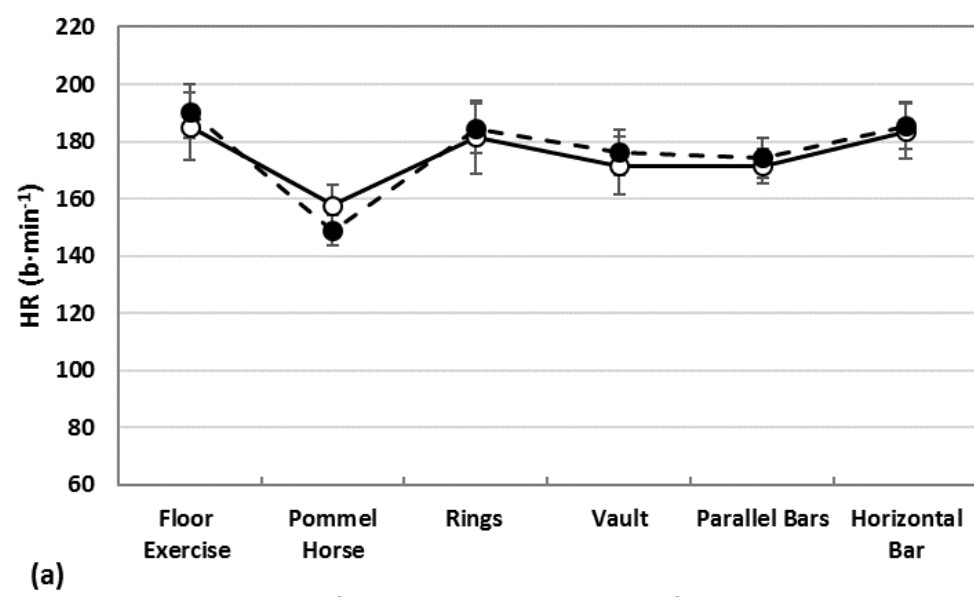

- - HRpeak Rotation 1 - 1 - HRpeak Rotation 2

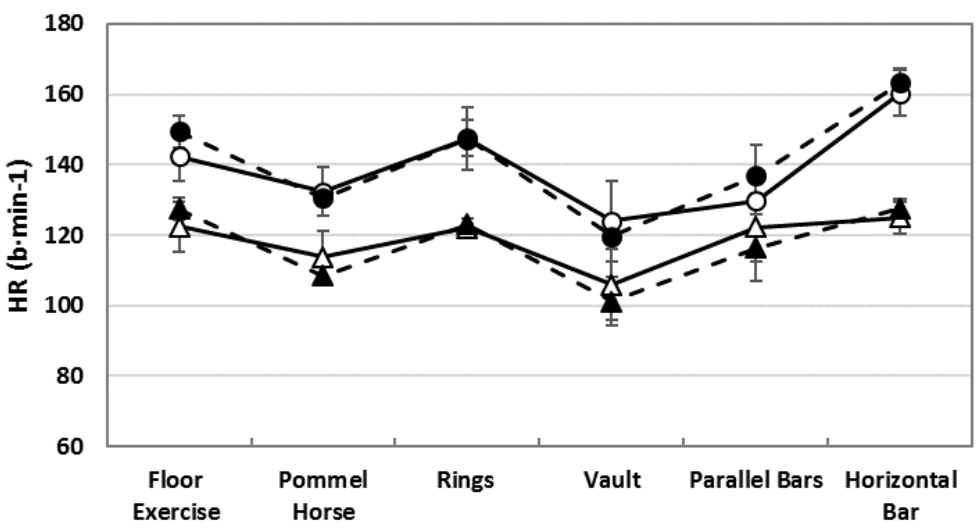

(b)

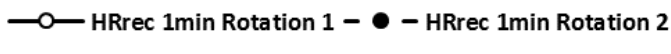

Figure 1

Percentage of the maximal heart rate during the competition: (a) in the apparatus routine, $(b)$ in the recovery period. 


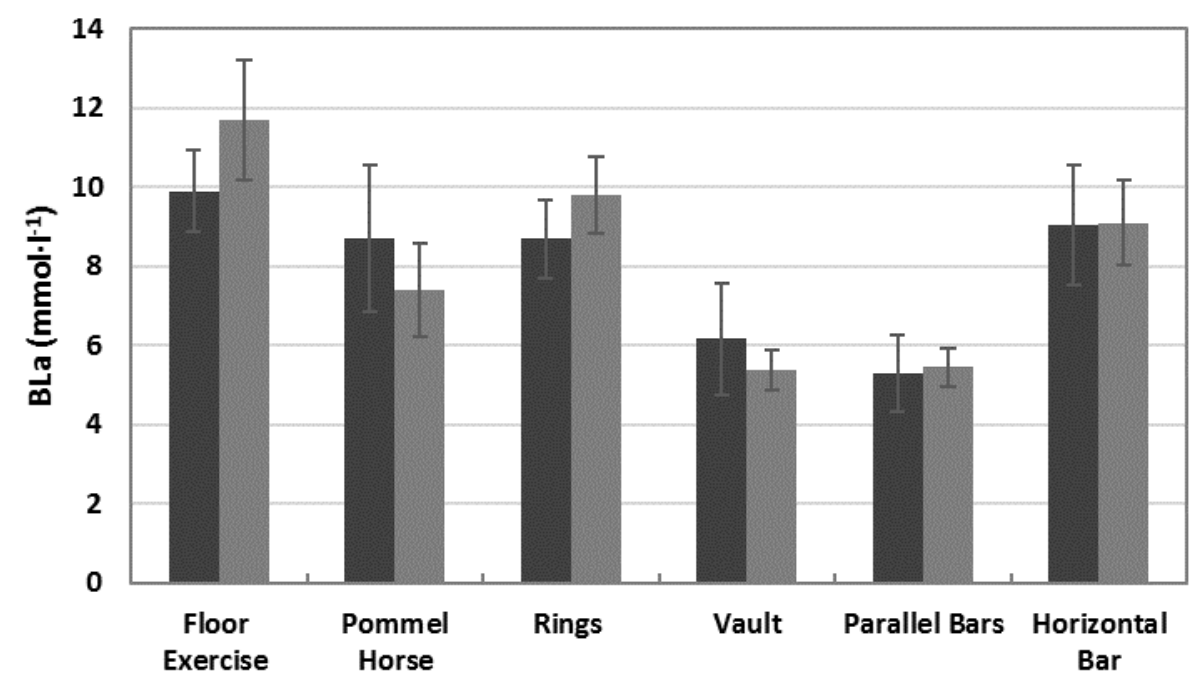

- BLa Rotation 1 BLa Rotation 2

Figure 2

Blood lactate concentration during the competitions.

\section{Discussion}

This study was a comparative investigation between two different Olympic rotation types in men's artistic gymnastics. The first sequence began with the $\mathrm{FX}$, then followed by the PH, SR, VT, PB, and ended up with the HB. The second one began with the $\mathrm{PH}$ followed by the SR, VT, PB, HB, and ended with the FX. The most important finding of this investigation was the significant metabolic variation considering the FX routines between the two rotations. The higher BLa value could be allocated to the gymnast's state of fatigue induced by the rotation order (i.e., the first apparatus in R1 versus the sixth in R2). We shall remind that the FX routine is the longest event and requires well developed agility, power, strength, dynamic and static flexibility as well as high acrobatic skills. The particularities of the physical and technical demands lead to significant metabolic consequences as shown by several authors (Goswami and Gupta, 1998; Jemni et al., 2001, 2003, 2011; Viana and Lebre, 2005). In addition to the $\mathrm{FX}$ routine, BLa concentration increased significantly during the SR events in R2, which could be explained by a higher anaerobic involvement compared with the same event performed in R1. The overall values of BLa concentration reported in our study $(7.96 \pm 1.81$ mmol. $\mathrm{l}^{-1}$ ) are similar to those reported by Groussard and Delamarche (2000) (7.02 \pm 2.63 mmol.1-1), but significantly higher than the ones reported by Jemni et al. $(2000,2003 b)(4.77 \pm 1.11$ mmol-1 $\left.{ }^{-1}\right)$. Performance analysis showed that, regardless of the rotation order, gymnasts received the same scores in all apparatuses except the scores of the FX being lower following R2 compared with R1. This decrease of the FX score could be explained by the fatigue accumulated following performance on the five previous apparatuses (PH, SR, VT, PB, and $\mathrm{HB}$ ) contrarily to R1, where gymnasts began with the FX. This assumption may be reinforced by the fact that, FX per se are physically demanding (Kirkendall, 1985; Petiot et al., 1987) and require a high level of explosive strength (FIG, 2001; Prados, 2005). Therefore, their placement at the end of the events might have affected the gymnasts' performance.

The results also indicate that $\mathrm{HR}_{\text {peak varied }}$ noticeably between three main apparatuses i.e., FX, VT, and PB $(p<0.05)$, but this difference 
remained statistically non-significant for the rest of the apparatuses. HRpeak was higher for the FX during R2 compared with R1 (190.60 $\pm 9.15 \mathrm{~b} \cdot \mathrm{min}^{-1}$ vs. $185.20 \pm 11.67 \mathrm{~b} \cdot \mathrm{min}^{-1}$, respectively). Again, this observation could be explained by the applied order of the apparatus (the sixth in R2). It is worth noting that the $\mathrm{HR}_{\text {peak }}$ values reported in the present study were similar to those reported by Hernández et al. (2009), Jemni (2011), Prados (2005) and Viana and Lebre (2005).

Analysis of the recovery heart rate also showed significant variations. Indeed, higher HRrec $1 \mathrm{~m}$ values were demonstrated after the FX, $\mathrm{PB}$, and $\mathrm{HB}$ routines following $\mathrm{R} 2$ compared with R1 $(p<0.05)$. Additionally, HRrec2m significantly differed following the VT and PB routines between the two rotations being higher following R1 compared with R2 $(p<0.05)$. Gymnasts showed better recovery after the FX, as well as after the $\mathrm{PB}$ and $\mathrm{HB}$ except after the VT events during R1 compared with R2 $(124.00 \pm 11.46$ $\mathrm{b} \cdot \mathrm{min}^{-1}$ vs $119.80 \pm 2.49 \mathrm{~b} \cdot \mathrm{min}^{-1}$, respectively). HRrec2m values were similar to those reported by Jemni (2010) and Jemni et al. (2003a, 2003b).

Collectively, the variation of cardiovascular and metabolic variables in the FX, $\mathrm{SR}$, and VT may be explained by the difference of the physical and metabolic requirements of each apparatus (Kirkendall, 1985; Petiot et al., 1987; Prados, 2005). For instance, FX refer substantially to explosive strength, the SR is largely oriented towards maximal strength, the VT is a speedbased apparatus, and the three remaining apparatuses (i.e., $\mathrm{PH}, \mathrm{PB}$, and $\mathrm{HB}$ ) are essentially power-strength (FIG, 2001; Prados, 2005). These particular apparatuses' fitness features may affect cardiovascular and metabolic responses and eventually performance during different rotation order.

\section{Acknowledgements}

Special thanks to all national team gymnasts and coaches for their valuable help and involvement in this study.

\section{References}

Brewin MA, Yeadon MR, Kerwin DG. Minimising peak forces at the shoulders during backward longswings on rings. Hum Movement Sci, 2000; 19(5): 717-736

Dallas G, Kirialanis P. Judges' evaluation of routines in men's artistic gymnastics. Sci Gymnastics J, 2010; 2(2): 49-58

Erdfelder E, Faul F, Buchner A. GPOWER: A general power analysis program. Behav Res Meth Ins C, 1996; 28(1): 1-11

\section{Conclusion}

The objective of this investigation was to compare cardiovascular and metabolic variables between two different types of the Olympic rotation order; one began with FX and finished with the $\mathrm{HB}$, while the other began with the $\mathrm{PH}$ and ended with FX. A secondary objective was to assess the effects of these two sequences on performance. Cardiovascular and metabolic variables were significantly different in routines performed on all apparatuses except the PH. The FX' score was significantly affected when gymnasts ended the competition with this apparatus, while scores obtained on the rest of the apparatuses remained unchanged. Our findings show that starting gymnastics competition with the FX implicates less cardiovascular and metabolic stress associated with better performance compared with the other rotation order; accordingly, the best gymnasts could have a slight advantage compared to the other athletes. In other words, the starting event is of utmost importance and could be decisive in the competition. The results reinforce the International Gymnastics Federation's decision to assign this sequence order to the six best gymnasts. The outcomes of this investigation could also provide coaches with a tactical tool that may help carefully manage the routines' difficulties of gymnasts according to their physical and technical capacity as well as their specialization. Nevertheless, there are four other types of the Olympic rotation order and it would be interesting to investigate them in order to know the effects of all the Olympic rotations on the gymnast's physiological variables. 
Goswami A, Gupta S. Cardiovascular stress and lactate formation during gymnastic routines. J Sport Med Physical Fitness, 1998; 38(4): 317-322

Grossfeld A. Changes during the 110 years of the world artistic gymnastics championships. Sci Gymnastics J, 2014; 6(2): 5-27

Groussard CY, Delamarche P. Physiological profile of young male gymnasts of national and international level. In $2^{\text {nd }}$ International Study Days of AFRAGA. Edited by Bardy BG, Pozzo T, Nouillot P, Tordi N, Delemarche P, Ferrand C et al., Rennes: France, 2000; 48-51

Heller J, Tuma Z, Dlouha R, Bunc V, Novakova H. Anaerobic capacity in elite male and female gymnasts. Acta Universitatis Carolinae. Kinanthropologica, 1998; 34: 75-81

Hernández TT, Balón GN, Galarraga AL. Relationship between Lactate, Heart rate and Duration in Selections Modes of Mens Artistic Gymnastics. Rev Cubana Med Deporte Cultura Fis, 2009; 4(3): 36-47

Hopkins WG. A. Scale of Magnitudes for Effect Statistics. A new view of statistics. Internet Society Sport Sci, 2002. Available at: http://www.sportsci.org/resource/stats/effectmag.html; accessed on August 07, 2015

International Gymnastics Federation. Age Group Developpement. Losane: FIG; 2001

International Gymnastics Federation. Code of points men's artistic gymnastics. Losane: FIG; 2009

Irurtia AA, Marina MA, Galilea PAB, Busquets AF. Heart rate rating during training in young gymnasts. Apunts: Educ Fisy deporte, 2007; 89(3): 64-74

Jemni M, Friemel F, Lechevalier J, Origas M. Bioenergetics of high-level gymnastics. Mov Sport Sci, 1998; 35: 105-106

Jemni M, Friemel F, Lechevalier JM, Origas M. Heart rate and blood lactate concentration analysis during a high-level men's gymnastics competition. J Strength Cond Res, 2000; 14(4): 389-394

Jemni M, Friemel F, Sands W, Mikesky A. Evolution of the gymnasts physiological profile during the last 40 years (review). Can J Appl Physiol, 2001; 26(5): 442-456

Jemni M, Friemel F, Sands W. Study of recovery between apparatus during four workouts in men's artistic gymnastics. Educ Phys Sport, 2002; 57: 57-61

Jemni M, Sands W, Friemel F, Cooke C, Stone M. Effect of gymnastics training on aerobic and anaerobic components in elite and sub elite men gymnasts. J Strength Cond Res, 2006; 20(4): 899-907

Jemni M, Sands WA, Friemel F, Delamarche P. Effect of active and passive recovery on blood lactate and performance during simulated competition in high level gymnasts. Can J Appl Physiol, 2003a; 28(2): 240-256

Jemni M, Sands WA, Friemel F, Le Chevalier JM. Heart Rate and blood lactate concentration as training indices for high level men's gymnasts. Elite Gymnastics J, 2003b; 26(4): 18-23

Jemni M. Recovery modalities: Effects on hormones' balance and performance. In 5th International Scientific Congress 'Sport, Stress, Adaptation'. Edited by S. National Sport Academy, Vasil Levski, Sofia: Bulgaria, 2010; 23-25

Jemni M. The Science of Gymnastics. Routledge: Taylor \& Francis Grp, 1-53; 2011

Kirkendall DT. Physiologic aspects of gymnastics. Clinics in sports medicine, 1985; 4(1): 17-22

Lange B, Halkin AS, Bury T. Physiologic requirements of high level gymnastics. Rev Med Liege, 2005; 60(12): 939-945

Marina M, Rodríguez FA. Physiological demands of young women's competitive gymnastic routines. Biol Sport, 2014; 31(3): 217

Papadopoulos G, Kaimakamis V, Kaimakamis D, Proios M. Main characteristics of rules and competition systems in gymnastics from 1896 to 1912. Sci Gymnastics J, 2014; 6(2): 29-40

Petiot B, Hoshizaki TB, Salmela JH. World identification systems for gymnastic talent. Montréal: Sport Psyche Publication, 109-121; 1987

Pineda-Espejel A, López-Walle J, Rodríguez JT, Villanueva MM, Gurrola OC. Pre-competitive anxiety and self-confidence in pan american gymnasts. Sci Gymnastics J, 2013; 5(1): 39-48

Prados JAL. Analysis of gymnasts lactate concentration: guidelines for action in reference to inter-exercises rest and post-workout intake. Apunts: Educ Fis deporte, 2005; 79(1): 86-93

Salmela JH. Psychology and mental training for gymnastics. In, M. Jemni Ed, The Science of Gymnastics. 
Routledge: Taylor \& Francis Grp, 107-163; 2011

Scanlan AT, Dascombe BJ, Reaburn PR. The construct and longitudinal validity of the Basketball Exercise Simulation Test. J Strength Cond Res, 2012; 26(2): 523-530

Viana J, Lebre E. Heart Rate Analysis during Men and Women Artistic Gymnastics. In $5^{\text {th }}$ International Conference of the AFRAGA. Edited by M. Jemni, and Robin JF. Hammamet: Tunisia, 2005; 81-83

\section{Corresponding author:}

\section{Dr. Bessem Mkaouer,}

Department of Sports and Physical Activities,

Higher Institute of Sport and Physical Education of Ksar Said,

Manouba 2010, Tunisia.

Tel.: + 216-23066716

E-mail: bessem_gym@yahoo.fr 